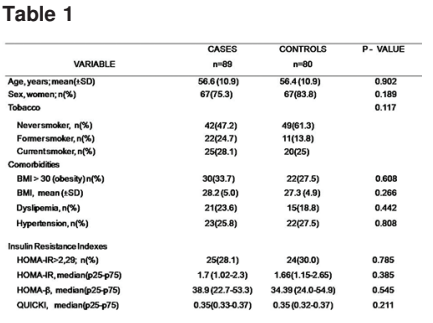

Acknowledgement: I thank the Rheumatology Spanish Society for Grant support in $2015-2017$ for this work.

Disclosure of Interests: Sara Manrique Arija Speakers bureau: ABBvie, MSD, Janssen, Lilly, Roche, Pfyzer, Novartis., Natalia Mena-Vázquez: None declared, Inmaculada Ureña : None declared, F. Gabriel JiménezNúñez: None declared, Clara Fuego-Varela: None declared, Antonio Fernandez-Nebro: None declared

DOI: 10.1136/annrheumdis-2019-eular.3674

\section{FRI0057 INSULIN RESISTANCE IN ELDERLY ONSET RHEUMATOID ARTHRITIS AND POLYMYALGIA RHEUMATICA}

Melania Martínez-Morillo, María Luisa Granada, Águeda Prior-Español, Anahy Brandy-Garcia, Susana Holgado Pérez, María Aparicio-Espinar, Laia Gifre, Anne Riveros-Frutos, Clara Sangüesa-Gomez, Jordi Camins-Fàbregas, Ivette Casafont-Solé, Annika Nack, Alejandro Olive, Lourdes Mateo Soria. Hospital Germans Trias i Pujol, Rheumatology, Badalona, Spain

Background: Rheumatoid arthritis (RA) patients have a higher insulin resistance (IR) and some studies report that it is present at diagnosis. Systemic inflammation has been pointed out as the reason. However, data on polymyalgia rheumatica (PMR) are controversial.

Objectives: To analyse IR in a group of untreated patients with a recent diagnosis of RA and PMR, and to establish predictive factors related with IR.

Methods: Longitudinal observational study of patients older than 60 years, newly diagnosed with elderly-onset AR (ACR/EULAR 2010) and PMR (ACR/EULAR 2012). Comparison with healthy control group of the same age. Inclusion: consecutive and voluntary. Exclusion: patients with insulindependent diabetes. Follow-up time: 12 months. The clinical-epidemiological, anthropometric and analytical characteristics were collected. IR was calculated by HOMA-IR [(homeostatic model assessment of insulin resistance $)=$ glucose $(\mathrm{mg} / \mathrm{dL})$ * insulin $(\mathrm{mUl} / \mathrm{L}) / 405]$ baseline and at 12 months. HOMA-IR>2.75 was considered IR (according to Spanish data). The statistical study was performed with Stata 15.1 .

Results: We recruited 42 patients with RA, 18 with PMR and 18 healthy controls. None of them had received treatment with corticosteroids or with DMARD at the baseline visit. Baseline characteristics are summarized in the table.

\begin{tabular}{lccc}
\hline & RA $(\mathbf{N}=\mathbf{4 2})$ & PMR $(\mathbf{N}=\mathbf{1 8})$ & P value \\
\hline Epidemiological data & & & \\
Women $\mathrm{n}(\%)$ & $18(42.9)$ & $15(83.3)$ & $\mathbf{0 . 0 0 1}$ \\
Age $($ mean $\pm \sigma)$ & $74.4 \pm 7.6$ & $76.4 \pm 5.2$ & 0.594 \\
Diabetes mellitus & $15(35.7)$ & $3(16.7)$ & 0.140 \\
BMI $\left(\mathrm{kg} / \mathrm{m}^{2}\right)$ & $27.7[25.1-30.5]$ & $26.5[24.0-29.1]$ & 0.393 \\
Abdominal perimeter $(\mathrm{cm})$ & $100[95-106]$ & $94[90-104]$ & 0.076 \\
Analytical data & & & \\
Glycohemoglobin\% & $6.1[5.9-6.4]$ & $5.8[5.6-6.5]$ & 0.107 \\
ESR (mm/1'ahora) & $49[36-75]$ & $52[42-69]$ & 0.508 \\
CPR (mg/L) & $24.4[7.1-44.1]$ & $22.1[12.4-45.9]$ & 0.670 \\
RF positive $\mathrm{n}(\%)$ & $14(33.3)$ & $1(5.6)$ & $\mathbf{0 . 0 2 3}$ \\
ACPA positive $\mathrm{n}(\%)$ & $13(30.9)$ & $2(11.1)$ & 0.104 \\
RF and ACPA positive $\mathrm{n}(\%)$ & $17(40.5)$ & $3(16.7)$ & 0.073 \\
Insulin resistance test & & & \\
HOMA-IR median[RIQ] & $3.6[2.1-5]$ & $2.1[1.6-3.4]$ & $\mathbf{0 . 0 0 4}$ \\
\hline
\end{tabular}

At baseline visit, $66.7 \%$ of patients with elderly-onset RA had IR, compared with $33.3 \%$ of controls $(p=0.024)$ and $27.8 \%$ of PMR $(p=0.006)$. Therefore, the prevalence of IR in patients with RA doubled that of controls and patients with PMR before starting treatment.

After 12 months of evolution and treatment, patients with RA and IR decreased from $66.7 \%$ to $51.2 \%$, not being statistically significant $(p=0.179)$. On the other hand, the percentage of patients with PMR and
IR remained the same $(27.8 \%)$. The differences in IR between RA and PMR at 12 months remained statistically significant $(p=0.048)$.

Given the results we decided to analyze the predictive factors related with IR only in the 42 patients with RA. In the univariate logistic regression analysis, the predictors of presenting IR were the BMI, the abdominal perimeter and the scapular girdle involvement. Specifically for BMI, for each of $2 \mathrm{~kg} / \mathrm{m} 2$ the probability of having IR was 1.24 times higher (OR=1.24, IC95\%: 1.12-1.37). Patients with scapular girdle involvement had a 6-fold increased risk of developing IR $(\mathrm{OR}=6.0,95 \% \mathrm{Cl}: 1.3$ 26.6). And for every 5 centimetres of abdominal perimeter the risk increased almost 4 times more $(\mathrm{OR}=3.9,95 \% \mathrm{Cl}: 2.9-5.1)$. In the multivariate analysis, the only independent factor to increase the IR was the abdominal perimeter $(\mathrm{aOR}=1.23, \mathrm{IC} 95 \%: 1.07-1.41)$.

Conclusion: Patients with elderly-onset RA have a higher IR than the general population. High IR in RA is present at diagnosis. IR in AR is not exclusively mediated by systemic inflammation, since patients with PMR do not have this increase. The predictors of presenting IR in late onset AR were $\mathrm{BMI}$, scapular girdle involvement and abdominal perimeter. Only the abdominal perimeter was shown as an independent factor.

Disclosure of Interests: None declared

DOI: 10.1136/annrheumdis-2019-eular.4267

\section{FRI0058 RHEUMATOID ARTHRITIS IS AN INDEPENDENT RISK FACTOR FOR DEVELOPING INFLUENZA REQUIRING HOSPITAL INPATIENT ADMISSION, COMPARABLE TO OLDER AGE AND GREATER THAN SMOKING, IN A LARGE, SINGLE-CENTRE COHORT}

Bonnia Liu ${ }^{1}$, Christopher Mcmaster ${ }^{1}$, David Liew ${ }^{1}, 2$, Russell Buchanan ${ }^{1,2},{ }^{1}$ Austin Health, Rheumatology, Melbourne, Australia; ${ }^{2}$ University of Melbourne, Medicine Melbourne, Australia

Background: RA patients are known to be at increased risk of serious infection(1), particularly for respiratory infections such as influenza which are known to be associated with increased morbidity and mortality(2). Currently RA patients do not have enhanced access to high-dose influenza vaccination in our jurisdiction, despite the reported benefit in RA(3) and enhanced access for patients older than 65 years old. The magnitude of the risk from RA compared to smoking or age greater than 65 years old remains incompletely understood.

Objectives: To examine the association of RA, smoking, and age greater than 65 years old with hospital inpatient admissions for influenza.

Methods: We examined general medical inpatient admissions in a large tertiary hospital between January 2012 and December 2018. Major confounders (smoking status, age and gender) were selected based on causal inference analysis using a directed acyclic graph. Natural language processing and ICD-10 codes were used to determine the diagnosis of rheumatoid arthritis, smoking status and influenza diagnosis. These variables were used in a multivariable logistic regression analysis. The strength of association was assessed using adjusted odds ratios and associated $95 \%$ confidence intervals.

Results: We assessed 19,010 patients with at least one general medical inpatient admission during the study period, of which 495 had at least one admission primarily for influenza (Table 1). Within this cohort, there were 3791 patients identified as active smokers and 731 with a history of RA. In the multivariable model, patients with a history of RA were more likely to have at least one admission for influenza (OR 1.65 [1.12 2.36]). This risk was comparable to that experienced by patients older than 65 years old in an unadjusted analysis (OR $1.62[1.29-2.04]$ ) and stronger than that experienced by smokers in an unadjusted analysis (OR 1.38 [1.12 - 1.69]).

Conclusion: RA patients are at independent risk of influenza leading to a hospital inpatient admission, with a magnitude comparable to that of patients aged over 65 years old and greater than that of smokers. Funding authorities should consider making influenza vaccination available for RA patients in a comparable way to that available to patients aged over 65 years old.

\section{REFERENCES}

[1] Listing, J., K. Gerhold, and A. Zink, The risk of infections associated with rheumatoid arthritis, with its comorbidity and treatment. Rheumatology (Oxford), 2013. 52(1): p. 53-61.

[2] Blumentals, W.A., et al., Rheumatoid arthritis and the incidence of influenza and influenza-related complications: a retrospective cohort study. BMC Musculoskelet Disord, 2012. 13: p. 158.

[3] Colmegna I, Useche M, Rodriguez K, Hudson M, Bernatsky S, Nedjar H Rahme E, Ward B. Efficacy of High-Dose Versus Standard-Dose Influenza 